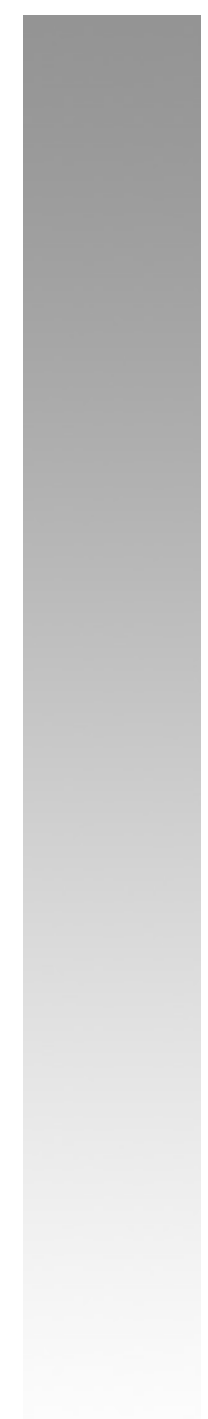

\title{
TRANSFUgUISMO: DICOTOMÍA ENTRE LA LEALTAD PARTIDARIA Y LA PARTICIPACIÓN POLÍTICA. UNA VISIÓN DESDE LOS PRECEDENTES JUDICIALES eN MÉxICO
}

\author{
The Tendency to Defect: The \\ DICOTOMY BETWEEN PARTY LOYALTY \\ and Political Participation. \\ A View Based on Judicial \\ Precedents in Mexico
}

TRANSFUgUISMO: DICOTOMIA ENTRE A LEALDADE PARTIDÁRIA E A PARTICIPAÇÃO POLÍTICA. UMA VISÃO A PARTIR DOS PRECEDENTES JUdICIAIS No MÉxICO

ENOC FRANCISCO MORÁN-TORRES* 


\section{RESUMEN}

El transfuguismo que ha caracterizado el sistema politico mexicano se ha convertido, en los últimos años, en un problema de orden constitucional a partir de ciertos matices que incluso han sido abordados por la máxima autoridad jurisdiccional en materia electoral en México, como lo es el Tribunal Electoral del Poder Judicial de la Federación, e incluso la Suprema Corte de Justicia de la Nación, puesto que este se ubica en la dicotomía entre el derecho de libertad individual de participación política y el propio de lealtad partidaria inexistente explícitamente en la normativa constitucional. Por lo anterior, la presente aportación académica versará sobre el análisis de la figura del transfuguismo, de forma preponderante desde la fase de la candidatura, a partir de algunos precedentes que han emitido autoridades jurisdiccionales en México, enmarcados en el sistema presidencial con el que se cuenta. Ello, sin menoscabo de señalar, de forma somera, cómo opera el transfuguismo en otros países.

\section{PALABRAS CLAVE}

Transfuguismo; libertad partidaria; participación política; restricción de derechos. 


\section{ABSTRACT}

The tendency to defect that has characterized the Mexican political system has become, in recent years, a problem of a constitutional nature, beginning with certain nuances that have been addressed by the highest judicial authority in electoral matters in Mexico; namely, the Electoral Court of the judicial branch of the Mexican federal system, and even by the Supreme Court of Justice of Mexico, since the matter is part of the dichotomy between the right to individual freedom in terms of political participation and the right to party loyalty, which does not exist explicitly in the constitution. Accordingly, this academic contribution deals with an analysis of the tendency to defect, predominantly in the candidacy phase, based on certain precedents that have been set by jurisdictional authorities in Mexico and framed within the country's presidential system. This is without neglecting to mention, in passing, how the tendency to defect operates in other countries.

\section{KEYWORDS}

Tendency to defect; party liberty; political participation; restriction of rights. 


\section{RESUMO}

O transfuguismo que tem caracterizado o sistema político mexicano tem se tornado, nos últimos anos, um problema de ordem constitucional a partir de certos matizes que, inclusive, são abordados pela máxima autoridade jurisdicional em matéria eleitoral no México, como são o Tribunal Eleitoral do Poder Judicial da Federação e a Suprema Corte de Justiça da Nação. Isso ocorre em virtude de que ele se encontra na dicotomia entre o direito de liberdade individual de participação política e o próprio de lealdade partidária inexistente explicitamente na normativa constitucional. Nesse sentido, esta contribuição acadêmica versará sobre a análise da figura do transfuguismo, de forma preponderante, desde a fase da candidatura, a partir de alguns precedentes que autoridades jurisdicionais no México têm emitido, delimitados no sistema presidencial com o qual se conta. Isso sem afetar a demonstração, de forma não exaustiva, de como opera o transfuguismo em outros países.

\section{PALAVRAS-CHAVE}

Liberdade partidária; participação política; restrição de direitos; transfuguismo. 
... transfuguismo, entendido en términos amplios, como una

deslealtad democrática. En efecto, dicho fenómeno perverso, constante en partidos politicos latinoamericanos y que ha conducido a aquello que la doctrina llama "electoral volatility", denota en el elegido una falta de firmeza ideológica, debilidad de convicciones, exceso de pragmatismo y anteposición de intereses personales y egoístas.

\begin{abstract}
SUMARIO: INTRODUCCIÓN; 1. TRANSFUgUISMO; 2. TRANSFUGUISMO Y SU RELACIÓN CON LOS DERECHOS FUNDAMENTALES; 3. TRANSFUgUISMO DESDE LOS PRECEDENTES JUDICIALES EN MÉXICO; 4. CONCLUSIONES; BiBLIOGRAFía.
\end{abstract}

\title{
INTRODUCCIÓN
}

El transfuguismo que ha caracterizado al sistema político mexicano se ha convertido, en los últimos años, en un problema de orden constitucional a partir de ciertos matices que, incluso, han sido abordados por la máxima autoridad jurisdiccional en materia electoral en México, como lo es el Tribunal Electoral del Poder Judicial de la Federación y la Suprema Corte de Justicia de la Nación, puesto que este se ubica en la dicotomia entre el derecho de libertad individual de participación política y el propio de lealtad partidaria, inexistente explícitamente en la normativa constitucional actual.

De ahí que resulta importante preguntarse si el transfuguismo, desde la perspectiva y las peculiaridades del sistema presidencial mexicano, puede y debe ser regulado para evitar que tránsfugas acudan de un partido a otro cuando no vean satisfechas sus aspiraciones a una candidatura, e incluso, sin afán de asemejarse al sistema parlamentario debido a que cada uno posee características propias, cuando un legislador local o federal que ha llegado con el respaldo de determinado partido político, cambia de fracción parlamentaria, afectando el principio de lealtad partidaria e incluso los derechos fundamentales que posee el ciudadano en el ámbito político.

En ese sentido, si bien la figura del transfuguismo representa una variable poco explorada - al menos en la doctrina mexicana-, sí ha ocupado diversos espacios para la reflexión, sobre todo en países con tradición parlamentaria. Situación que provoca, en la presente aportación académica, partir del cuestionamiento sobre la necesidad de su estudio con base en algunos precedentes judiciales que han esbozado matices respecto a su concepción como elemento que impacta, no solo en el sistema politico y electoral, sino en los derechos fundamentales de los ciudadanos que votan y son votados, al entrar en la dicotomía entre la lealtad partidaria y la participación política.

Por lo anterior, la presente aportación académica versará sobre el análisis de la figura del transfuguismo, de forma preponderante desde la fase de la candidatura, a partir de algunos precedentes que han emitido autoridades jurisdiccionales en México, enmarcados en el sistema presidencial con el que se cuenta. Ello, sin menoscabo de señalar, de forma somera, cómo opera el transfuguismo en otros países. 


\section{TRANSFUguismo}

Para Daniel Zovatto, el transfuguismo es una conducta que atenta contra la voluntad popular y constituye incluso un ejemplo de corrupción personal. ${ }^{1}$ Este fenómeno debilita el sistema de partidos y coadyuva a la falta de credibilidad del elector en sus representantes populares, sobre todo aquellos ciudadanos votantes que vincularon las propuestas del candidato con la plataforma electoral del partido político que los postuló, o la agenda legislativa impulsada por aquel, incluso desde la fase de la campaña.

De hecho, doctrinalmente, el transfuguismo se ha ubicado como figura tanto del sistema presidencialista como del parlamentario. ${ }^{2}$ Dado que cada uno de estos exhibe sendas diferencias, es necesario enunciar algunas para contextualizar el abordaje del tema que nos ocupa.

En esa tesitura, entre algunas de las diferencias que presentan ambos regimenes se encuentran, verbigracia, las siguientes: en el sistema parlamentario, la única institución legitimada democráticamente es el Parlamento y el Gobierno emerge de la aprobación de aquel, mientras que en el presidencial, el presidente es a su vez el jefe de Estado y jefe de Gobierno, y el Congreso limita sus funciones casi exclusivamente a las legislativas. ${ }^{3}$

Asimismo, para Carpizo, el régimen parlamentario posee, de manera enunciativa mas no limitativa, los elementos siguientes: los miembros del gabinete lo son también del Parlamento; el gabinete subsistirá siempre y cuando cuente con el apoyo de la mayoría parlamentaria; y entre el Parlamento y el Gobierno existe un control mutuo. Por su parte, el régimen presidencial presenta tres características esenciales: 1) la separación de poderes entre ejecutivo y legislativo es nítida; 2) los periodos para el desempeño en los poderes de referencia son fijos; 3) existen entre ambos poderes controles mutuos. ${ }^{4}$

Dieter Nohlen señala que mientras que en el parlamentarismo existe una estrecha vinculación entre la mayoría parlamentaria y el Gobierno, en el presidencialismo se presenta una separación entre el Parlamento y el propio Gobierno. ${ }^{5}$

1 Daniel Zovatro G., "Reforma político-electoral e innovación institucional en América Latina durante la tercera ola democrática (1978-2009)”, p. 199, en http://eprints.ucm.es/17751/1/T34113.pdf

2 Para Ricardo Espinoza, la teoria del sistema parlamentario surge en Inglaterra, sus peculiaridades aparecieron en Gran Bretaña en el siglo XVIII y el sistema presidencial se inspira en el modelo inglés del cual conserva algunos elementos fundamentales y modifica otros. Véase Ricardo EspinozA Toledo, "Sistemas parlamentario, presidencial y semipresidencial”, en Cuadernos de divulgación de la cultura democrática 20 (2012), pp.17-28.

3 Instituto de Investigaciones Legislativas del Senado de la República, Parlamentarismo y presidencialismo. Estudio comparado, p. 4-6, en http://www.senado.gob.mx/ibd/content/lineas/docs/varios/Parlamentarismo_Presidencialismo.pdf

4 Jorge CARPIzo, "Características esenciales del sistema presidencial e influencias para su instauración en América Latina”, en Cuestiones Constitucionales, 115, en http://historico.juridicas.unam. $\mathrm{mx} / \mathrm{publica/rev/boletin/cont/115/art/art2.htm}$

5 Dieter NoHLEn, "El presidencialismo comparado", Revista Instituto de Altos Estudios Europeos 1, en http://www.iaee.eu/riaee/num1/riaeelart1.pdf 
En el primer caso se alude a transfuguismo cuando el integrante de un grupo parlamentario, durante su gestión, se cambia a otro grupo mientras que, en el segundo, se vincula al candidato que cambia de partido político durante el proceso de selección de candidatos al interior del partido político, cuando este no se ha visto favorecido con la designación de la candidatura a la que aspiraba y decide buscarla en otro instituto político para tener la posibilidad de participar en la contienda electoral en ciernes.

En ambos casos, la figura en comento tiene impacto en la representación política, entendida esta, desde la perspectiva de Woldenberg y Becerra, como el resultado del proceso mediante el cual una comunidad ha seleccionado y ha elegido a alguno de sus miembros para que se hagan cargo, defiendan y argumenten los temas y los intereses que son comunes. ${ }^{6}$ Empero, para Criado de Diego, la representación política sería eficaz a la hora de intereses generales, pero ineficaz en la labor de mediación e integración en el Estado de los intereses empíricos. ${ }^{7}$

Aunado a lo anterior, para Perícola y Linares los representantes portan una representatividad configurada en las urnas sobre la base de la adscripción politica a un partido politico, y cuando no se integran al grupo parlamentario que les corresponde o, integrados, deciden cambiarse a otro, el transfuguismo se convierte en un distorsionador de la representación política. ${ }^{8}$

De igual manera, para los referidos autores el transfuguismo puede ser inicial o sobreviniente, en el primer caso se materializa cuando el tránsfuga cambia desde el inicio del ejercicio del cargo para el cual fue postulado por el partido político y, en el segundo, cuando durante el desempeño de funciones realiza el cambio de grupo al que originalmente se encontraba adscrito. ${ }^{9}$

Un elemento toral del transfuguismo es el tránsfuga, individuo que opera o materializa la figura en comento mediante el cambio de partido, mismo que puede ser clasificado como falso, puro, estratégico o independiente. Ello desde la tipología de transfuguismo propuesta por Jiménez Badillo: el falso tránsfuga abandona el grupo por razones personales o por haber recibido invitación a participar en

6 José Woldenberg y Ricardo Becerra, "Representación politica”, en Diccionario Electoral, Centro de Asesoria y Promoción Electoral del Instituto Interamericano de Derechos Humanos, en http:// www.iidh.ed.cr/comunidades/redelectoral/docs/red_diccionario/representacion\%20politica.htm. Para Brunet, el concepto moderno de representación reside en la ausencia de cualquier mandato y en la afirmación de la soberanía del representante. Véase Pierre BRunET, "Acerca del concepto de representación política”, en Revista Internacional de Pensamiento Político 7 (2012), p. 257, en http://pensamientopolitico.org/Descargas/RIPP07245261.pdf

7 Marcos CRIAdo DE DIEGO, "Sobre el concepto de representación política: lineamientos para un estudio de las transformaciones de la democracia representativa”, en Revista Derecho del Estado 28, 2012, p. 80, en http://revistas.uexternado.edu.co/index.php/derest/article/view/3180.

8 María Alejandra Perícola y Gonzalo Joaquín Linares, "El transfuguismo político como elemento distorsionador de la representación politica”, en Revista Pensar en Derecho, p. 249, http://www. derecho.uba.ar/publicaciones/pensar-en-derecho/revistas/3/el-transfuguismo-politico-comoelemento-distorsionador-de-la-representacion-politica.pdf. Idem, p. 251. 
algún cargo politico o administrativo; el tránsfuga puro se integra a la bancada mayoritaria o del principal partido de oposición; el tránsfuga estratégico se suma a otros legisladores para crear otra bancada, mientras que el tránsfuga independiente se autodenomina legislador independiente. ${ }^{10}$

En ese sentido, quizá la invocación en la doctrina más común para aludir a la figura del transfuguismo es en el ámbito parlamentario, que Mershon y Shvetsova entienden como: ${ }^{11}$

...aquellas situaciones en las cuales un legislador por diversas razones decide abandonar o es expulsado de su bancada legislativa sin renunciar a su escaño. En una visión más politológica, el transfuguismo se refiere a las evoluciones del sistema de partidos durante los periodos interelectorales, es decir los cambios en la distribución de escaños parlamentarios que ocurren durante un periodo constitucional.

Lo anterior no es óbice para que se asocie generalmente el transfuguismo con el fenómeno de la migración legislativa, ${ }^{12}$ característico no solo en Centroamérica sino en el resto de América Latina. Situación que atenta contra la representación política y, en muchos de los casos, desanima al elector al no encontrar explicación de las razones que motivaron a un legislador que, habiendo llegado a un escaño o curul con la plataforma de un partido político y el voto ciudadano, durante el ejercicio del mismo cambia de bancada o grupo, sin mediar mayor explicación a sus representados.

Por su parte, en España el fenómeno del transfuguismo, desde la óptica de Jorge de Esteban, regularmente se produce durante la misma legislatura y tiene efectos inmediatos sobre la marcha del sistema, trayendo como perjuicios los siguientes: falsea la representación política, debilita el sistema de partidos, perjudica la gobernabilidad, favorece la corrupción y deteriora la cultura politica democrática. ${ }^{13}$

En realidad, el transfuguismo, a partir de la consideración de que el tránsfuga es aquel que cambia de partido, no es privativo del sistema parlamentario puesto que también se puede presentar en el sistema presidencial desde dos vertientes: la primera cuando un precandidato aspira alcanzar la candidatura de un partido político y, al no verse beneficiado con ella, migra a otro instituto político y, la segunda, cuando un representante popular proveniente de un proceso electoral,

10 Margarita Jiménez BADILlo, “Transfuguismo legislativo en Centroamérica”, SOMEE, 2014, pp. 4-5, en http://www.somee.org.mx/download.php?t=2\&c=3\&h=1066d7ae92e1d5621c6f1cb21e976306 acdc37fe.

11 Citado por Dennis P. Petri y Jean-Paul Vargas. Véase Dennis P. Petri y Jean-Paul Vargas, "cultura parlamentaria y disciplina partidaria: la institucionalidad informal del transfuguismo en Centroamérica”, en www.ort.edu.uy/facs/.../95/culturaparlamentariaydisciplinapartidaria.doc.

12 Margarita JimÉnez BADILlo, Transfuguismo legislativo en Centroamérica, op. cit., p. 5, nota 11.

13 Jorge DE Esteban, "El fenómeno español del transfuguismo político y la jurisprudencia constitucional", en Revista de Estudios Politicos 70 (1990), en http://webcache.googleusercontent.com/search?q=ca che:9mcugzpzgl4J:dialnet.unirioja.es/descarga/articulo/27081.pdf $+\& \mathrm{~cd}=1 \& \mathrm{hl}=\mathrm{es} \& \mathrm{ct}=\mathrm{clnk} \& \mathrm{gl}=\mathrm{mx}$ 
durante el ejercicio del cargo, e incluso en los albores de este, se cambia a otro grupo parlamentario o fracción legislativa. ${ }^{14}$

Así pues, dicha circunstancia, como se mencionó, ha sido abordada y duramente criticada por la doctrina, e incluso regulada en algunos países para evitar que un representante popular migre de bancada o grupo parlamentario. Sobre el particular, países como Bolivia consideran como grave el hecho que un legislador se incorpore a un partido distinto después de su elección. Por su parte, en Francia, a nivel reglamentario de la Asamblea Nacional hay una consecuencia para el tránsfuga consistente en la acotación de su derecho para participar en comisiones. Mientras que en España, la referida figura se encuentra prevista a nivel de acuerdos entre los partidos políticos y el Gobierno de ese país iberoamericano. Finalmente, en Brasil se permite una sanción al tránsfuga por parte del partido político, consistente en la pérdida del cargo, si no mediare causa justa. ${ }^{15}$

En cambio, no pasa desapercibido que en el caso de México, producto de la Reforma Constitucional en Materia Política-Electoral del año 2014, se estableció en el artículo 59 de la Constitución General de la República, como candado para acceder a la nueva figura de la elección consecutiva, en el caso de diputados federales y senadores, que estos fueran presentados por el mismo partido político que los postuló, salvo que hayan renunciado o perdido su militancia antes de la mitad de su mandato. ${ }^{16}$

Lo anterior, en aras de fortalecer el sistema de partidos o, como algunos aducen, de fortalecer el sistema representativo a partir de la identificación del sujeto con la ideologia partidaria y con la plataforma electoral que le dotó de estructura e impulsó para llegar al poder por la vía de los partidos políticos, a pesar de que ello implique coartar la libertad de participación política y el ejercicio del derecho fundamental de ser votado en su vertiente de ocupar el cargo para el que fue electo.

\section{EL TRANSFUGUISMO Y SU RELACIÓN CON LOS DERECHOS FUNDAMENTALES}

La doctrina no es la única que se ha ocupado del análisis de la figura del transfuguismo, la propia Corte Constitucional de Colombia, al resolver la demanda de

14 En el caso de México, particularmente en el Senado de la República, en este año 2017, considerando que la LXIII Legislatura se instaló en el año 2012 y concluirá su ejercicio en 2018, se presentó el caso de 12 senadores que pertenecían al grupo parlamentario del Partido de la Revolución Democrática y abandonaron dicha bancada para incorporarse, algunos de ellos, a la correspondiente del Partido del Trabajo, y otros tantos aún permanecen sin grupo parlamentario.

15 Christine Weidenslaufer, Transfugismo politico. Derecho comparado, Santiago de Biblioteca del Congreso Nacional, en https://www.bcn.cl/asesoriasparlamentarias/buscar?texto=Transfugismo+pol $\%$ C3\%ADtico.+Derecho+Comparado

16 Secretaría de Gobernación, Diario Oficial de la Federación. Decreto por el que se derogan reforman y adicionan diversas disposiciones de la Constitución Política de los Estados Unidos Mexicanos, en materia política-electoral, 10 de febrero de 2014, en http://www.dof.gob.mx/nota_detalle.php?co digo $=5332025 \&$ fecha $=10 / 02 / 2014$ 
inconstitucionalidad contra algunas expresiones contenidas en diversos artículos de la Ley 1437 de 2011, misma que fue identificada como sentencia C-334/2014 del 4 de junio de 2014 , determinó la inexequibilidad ${ }^{17}$ de la expresión "al momento de la elección”. Ello, toda vez que la ejecutoria en comento invocó un precedente de la misma Corte en el que habia determinado que:18 "la prohibición de la doble militancia y del transfuguismo político, en los términos antes expuestos, constituye herramientas de primera línea para la consecución del fin constitucional de fortalecimiento de los partidos y movimientos políticos, basado en el aumento del estándar de disciplina de sus miembros e integrantes”.

Asimismo, la sentencia de referencia señaló que la intención del constituyente colombiano era fortalecer los partidos politicos, necesario para la preservación del principio democrático representativo ante las amenazas de prácticas personalistas. Por lo que, desde la perspectiva de la citada instancia colombiana, el transfuguismo es una modalidad de "deslealtad democrática" debido a que se basa en un fraude a la voluntad del elector.

Adicionalmente, en un precedente identificado como sentencia C-342 de 2006, la referida Corte Constitucional había considerado que, en la prohibición de la doble militancia resultaba necesario distinguir a los destinatarios del precepto cuestionado: ciudadanos, miembros e integrantes de partidos y movimientos. Cabe destacar que para la multicitada instancia jurisdiccional en la ejecutoria de mérito, son precisamente los integrantes de partidos y movimientos, quienes ejercen cargos de elección popular, los destinatarios de la prohibición de la doble militancia.

Así, desde dicha perspectiva, el transfuguismo resulta aplicable al servidor público, cuyo origen es la elección popular, que cambia de ideologia o del partido o movimiento que lo postuló y no al ciudadano que cambia de opción ideológica.

En ese contexto, la importancia de los precedentes invocados, ut supra, estriba en que la Corte Constitucional de la República de Colombia, atendiendo a la intención del Constituyente y de las reformas subsecuentes, privilegió el fortalecimiento de los partidos politicos mediante la preeminencia de la disciplina partidaria sobre la libertad que poseen, sobre todo los integrantes de los institutos políticos, para cambiar de partido o bancada durante el ejercicio del cargo. Ello, sin menoscabar la libertad que tienen los ciudadanos de cambiar de ideología y de partidos cuando estos no se ubiquen en los supuestos de restricción.

17 Clase de sentencia emitida por la Corte Constitucional en la que se manifiesta que una ley es contraria a la Constitucional Política de Colombia y, por tanto, debe desaparecer total o parcialmente del orden jurídico. Congreso de la República de Colombia, Glosario, en http://www.senado.gov.co/ glosario/Glosario-1/I/

Sobre el particular, el artículo 275, numeral 8, de la Ley en comento, establecía como causal de anulación electoral que los actos de elección o de nombramiento son nulos en los eventos previstos en el artículo 137 del Código de Procedimiento Administrativo y de lo Contencioso Administrativo y, además, cuando tratándose de la elección por voto popular, el candidato incurra en doble militancia política al momento de la elección.

18 Corte Constitucional de la República de Colombia, sentencia C-334/14, 4 de junio de 2014, en http://www.corteconstitucional.gov.co/RELATORIA/2014/C-334-14.htm 
Lo expuesto adquiere especial relevancia cuando se advierte que la Corte Interamericana de Derechos Humanos ha señalado que los derechos fundamentales solo pueden ser restringidos bajo criterios de razonabilidad. Por lo que, para su ejercicio, no deben ser impuestas restricciones indebidas que dejen de optimizar su goce, ${ }^{19}$ a partir de la consideración de que es un derecho fundamental del ciudadano participar en los asuntos públicos de su país. ${ }^{20}$

Efectivamente, la Corte Interamericana ha señalado lo siguiente: ${ }^{21}$

Los derechos políticos son derechos humanos de importancia fundamental dentro del sistema interamericano que se relacionan estrechamente con otros derechos consagrados en la Convención Americana como la libertad de expresión, la libertad de reunión y la libertad de asociación y que, en conjunto, hacen posible el juego democrático. La Corte destaca la importancia que tienen los derechos políticos y recuerda que la Convención Americana, en su artículo 27, prohíbe su suspensión y la de las garantías judiciales indispensables para la protección de estos.

Bajo esa tesitura, un precedente importante sobre la restricción de los derechos políticos es el caso Yatama vs. Nicaragua, ${ }^{22}$ en el que la Corte razonó que no se puede limitar el ejercicio de los derechos politicos, en tanto que la reglamentación o las disposiciones normativas de estos derechos impidan la participación en la toma de decisiones y en el acceso a cargos públicos. La reglamentación y aplicación de requisitos para el ejercicio de los derechos políticos no representan, por sí mismos, una restricción indebida, ya que estos deben observar los principios de legalidad, necesidad y proporcionalidad. Dichos requisitos, continúa la Corte, para poder ejercer los derechos políticos, deben contenerse en una porción normativa clara, en la cual los ciudadanos se encuentren en posibilidad de participar en las elecciones para acceso a los cargos públicos. Estas mismas no deben ser discriminatorias, basarse en criterios razonables, y atender un propósito útil y oportuno para satisfacer un interés público.

Igualmente, la Corte Interamericana señala que los Estados pueden establecer estándares y requisitos mínimos para la participación de los ciudadanos en la

19 Véase artículo 23 de la Convención Americana de los Derechos Humanos, en http://www.bjdh.org. $\mathrm{mx} /$ interamericano/busqueda?q=restricci\%F3n\%20de\%20derechos\&or=true\#mapa_listado

20 Corte Interamericana de Derechos Humanos, Caso Argüelles y otros vs. Argentina. Excepciones Preliminares, Fondo, Reparaciones y Costas. Sentencia de 20 de noviembre de 2014. Serie C No. 288, párr. 221 .

21 Corte Interamericana de Derechos Humanos, Caso Castañeda Gutman vs. Estados Unidos Mexicanos. Excepciones Preliminares, Fondo, Reparaciones y Costas. Sentencia de 6 de agosto de 2008. Serie C No. 184, párr. 140.

22 Corte Interamericana de Derechos Humanos. Caso Yatama vs. Nicaragua. Excepciones Preliminares, Fondo, Reparaciones y Costas. Sentencia de 23 de junio de 2005, en http://www.corteidh. or.cr/docs/casos/articulos/seriec_127_esp.pdf

La demanda deriva de la exclusión que se hizo a los candidatos presentados por el partido político regional indígena Yatama, de participar en las elecciones, en razón de que no cumplieron con requisitos que establecía la Ley electoral, respecto de la participación en las elecciones únicamente por medio de partidos políticos, así como la presentación de candidatos, por parte de los partidos políticos, en al menos $80 \%$ de los municipios de la respectiva circunscripción electoral. 
política, solo que estos deben ser razonables tomando en cuenta los principios de la democracia representativa.

Ahora bien, en el caso de México, el Tribunal Electoral del Poder Judicial de la Federación en México, al resolver el juicio para la Protección de los Derechos Político-Electorales del Ciudadano, radicado SUP-JDC-695/2007, abordó el tema de la restricción de los derechos políticos y argumentó que los derechos políticoelectorales no son absolutos e ilimitados, pues estos pueden ser objeto de ciertas restricciones, siempre que estén previstas en la legislación, no sean irracionales, injustificadas, desproporcionadas, o que se traduzcan en privar de su esencia a cualquier derecho, fin, principio o valor constitucional o electoral fundamental; estas restricciones deben garantizar el ejercicio efectivo de tales derechos y evitar limitarlos o suprimirlos en mayor medida que lo permita la Constitución y los tratados internacionales. ${ }^{23}$

Además, que cualquier condición que se imponga al ejercicio de los derechos político-electorales, señala la Sala Superior, deberá basarse en calidades inherentes a la persona, así como criterios objetivos y razonables. Por lo que la instancia federal en comento consideró que respecto a las calidades, los requisitos, las circunstancias o las condiciones para el ejercicio del derecho, de los tratados internacionales, se advertía que estas limitaciones son de carácter personal, intrínsecas al sujeto, y que deben seguir esta naturaleza, esto no implica la imposibilidad de establecer limitaciones que salvaguarden principios constitucionales de las elecciones, pero estas deben ser necesarias, proporcionales e idóneas.

En efecto, la referida instancia jurisdiccional estima que ocupar el cargo de presidente municipal no es inherente a una persona, pues este se obtiene de reunir requisitos previstos en la legislación correspondiente y ser electo en un proceso electoral; esto no implica contar con una calidad de naturaleza personal, toda vez que el elemento distintivo es haber resultado vencedor en una contienda electoral. Por lo que la referida Sala concluye que ocupar ese cargo no es razón suficiente para limitar el derecho fundamental de ser votado, puesto que este solo implica otro tipo de atributos o circunstancias del sujeto, derivadas del ejercicio del derecho de ser votado y elegido por el voto popular.

23 Tribunal Electoral del Poder Judicial de la Federación, sentencia del expediente SUP-JDC-695/2015, 6 de julio de 2007, http://www.te.gob.mx/documentacion/publicaciones/Serie_comentarios/09_ SUP-JDC-0695-2007.pdf

El juicio ciudadano fue promovido por Jorge Hank Rhon en contra del Tribunal de Justicia Electoral del Poder Judicial del Estado de Baja California, dado que en la sentencia de fecha 21 de junio de 2007, revocó el acuerdo de registro para candidato a gobernador del estado de la coalición "Alianza para que vivas mejor", conformada por los partidos políticos nacionales: Revolucionario Institucional, Verde Ecologista de México y Estatal de Baja California, por considerar que existía la prohibición para que un presidente municipal, que aún no concluía el periodo para el que fue electo, pudiera ser registrado como candidato para contender en la elección de gobernador. 
A mayor abundamiento respecto a los principios de proporcionalidad y razonabilidad, el propio Tribunal Constitucional Español ha señalado que los derechos no son absolutos: ${ }^{24}$

\begin{abstract}
No puede aceptarse la tesis [...] de que los derechos reconocidos o consagrados por la Constitución solo pueden quedar acotados en virtud de limites de la propia Constitución o por la necesaria acomodación con el ejercicio de otros derechos reconocidos y declarados igualmente por la Norma Fundamental. Una conclusión como esta es demasiado estricta y carece de fundamento en una interpretación sistemática en la Constitución y en el Derecho constitucional, sobre todo si al hablar de límites derivados de la Constitución, esta expresión se entiende como derivación directa. La Constitución establece por sí misma los límites de los derechos fundamentales en algunas ocasiones. En otras ocasiones el limite del derecho deriva de la Constitución solo de una manera mediata o indirecta, en cuanto que ha de justificarse por la necesidad de proteger o preservar no solo otros derechos constitucionales, sino también otros bienes constitucionalmente protegidos.
\end{abstract}

De lo expuesto se colige que el fenómeno del transfuguismo, además de estar en la dicotomía entre la lealtad partidaria y la participación politica, también tiene una estrecha relación con los derechos fundamentales, ${ }^{25}$ particularmente los relativos a los derechos políticos de los tránsfugas y de los propios electores, circunstancia que si bien es cierto, por si misma implicaría la necesidad de estudios posteriores, sobre el particular también lo es que, en en el caso del sistema jurídico mexicano, ha sido esbozado a partir de diversos precedentes judiciales que se abordan en el apartado siguiente.

\title{
3. TRANSFUgUISMO DESDE LOS PRECEDENTES JUdiCiALES EN MÉXICO
}

La etapa moderna de México se ha caracterizado por desarrollos legislativos tendientes al fortalecimiento de los procesos electorales, prueba de ello son las reformas constitucionales en el ámbito político y electoral de 1970, 1986, 1990, 1993, 1996, 2007, 2011 y, la más reciente, de 2014. Esta circunstancia ha permitido contar con órganos administrativos como el Instituto Nacional Electoral y sus correspondientes organismos públicos electorales locales, así como los jurisdiccionales de las entidades federativas, como el Tribunal Electoral del Poder Judicial de la Federación y los Tribunales Electorales Locales, además de configurar un nuevo sistema

24 Encarnación Roca Trías y Ma Ángeles Ahumada Ruiz, "Los principios de razonabilidad y proporcionalidad en la jurisprudencia constitucional española”, p. 7, en http://www.tribunalconstitucional. es/es/actividades/Documents/XV\%20Trilateral/PONENCIA.pdf

25 Para Bobbio, los derechos fundamentales "anteriores a los deberes" son aquellos que el individuo como tal puede reivindicar frente o contra, o incluso frente a la colectividad y al poder que la gobierna. Cabe destacar que para el mismo Bobbio, los "derechos anteriores a los deberes" son aquellos que no son consecuencia de la existencia de determinados deberes lógicamente antecedentes de los mismos, sino que han sido concebidos como originarios. Véase Michelangelo Bovero, "La protección supranacional de los derechos fundamentales y la ciudadanía", en Cuadernos de divulgación de la justicia electoral 19 (2013), p. 23. 
nacional electoral a partir de procesos electorales complicados, en los que se eligió presidente de la República, como el de 2006 y el último de 2012.

Del mismo modo, la democracia electoral se ha convertido en el eje de la regulación legal que busca establecer reglas de competencia más claras a través de la previsión normativa de los partidos políticos, candidatos y organismos electorales, privilegiando a esta incluso sobre la propia democracia participativa. Es por ello que la toma de decisiones en el Poder Legislativo, tanto del ámbito federal como local, se ha convertido en una de las más altas prioridades de las entidades de interés público, ${ }^{26}$ puesto que es desde dicha instancia que tiene como finalidad representar las voces de los habitantes y las entidades federativas de México, donde se establecen las reglas bajo las cuales se disputará el poder político en la arena electoral. Particularmente, en el caso del orden federal, el Senado de la República designará a los ministros del Poder Judicial de la Federación y aquellos magistrados electorales que revisarán, en última instancia, la elección de alcaldes, legisladores locales y federales, gobernadores e incluso calificarán la elección presidencial y, eventualmente, declararán su validez.

Ahora bien, por rigor de método es pertinente señalar que la Constitución General de la República Mexicana establece como derechos del ciudadano poder ser votado para todos los cargos de elección popular, teniendo las calidades que establezca la ley. El derecho a solicitar el registro de candidatos ante la autoridad electoral corresponde a los partidos políticos así como a los ciudadanos que soliciten su registro de manera independiente y cumplan con los requisitos, condiciones y términos que determine la legislación así como asociarse para formar parte en forma pacífica en los asuntos políticos del país. ${ }^{27}$

En ese sentido, si bien es cierto que diversos órganos jurisdiccionales de México han realizado esfuerzos por otorgar interpretaciones progresistas en lo relativo a la protección y maximización de los derechos políticos, también lo es que, a nivel legislativo, se han aprobado disposiciones normativas para acotarlos, en aras de priorizar la partidocracia, y que han pretendido inhibir el transfuguismo desde las propias candidaturas, bien sea imponiendo requisitos para que un militante solo pueda ser postulado por el partido politico al que pertenece o que, para efectos de la elección consecutiva, solo pueda ser postulado por la entidad de interés público que lo postuló e incluso impugnando la candidatura o el triunfo de un candidato que compitió por un partido político distinto al que militaba. Preceptos normativos que han sido sometidos al tamiz de constitucionalidad por parte de la Suprema Corte de Justicia de la Nación, y del propio Tribunal Electoral del Poder Judicial de la Federación. La primera, como cabeza de uno de los poderes de la Unión, particularmente el Judicial, y el segundo, como máxima autoridad jurisdiccional en materia electoral. ${ }^{28}$

26 El artículo 41, párrafo segundo, fracción I de la Constitución Política de los Estados Unidos Mexicanos define a los partidos políticos como entidades de interés público.

27 Cfr. artículo 35, fracciones II y III de la Constitución Política de los Estados Unidos Mexicanos.

28 Cfr. artículos 94 y 99 de la Constitución Política de los Estados Unidos Mexicanos. 
En efecto, respecto de la Suprema Corte, un precedente que no puede obviarse es el emanado de la Acción de Inconstitucionalidad 158/2007 relativa a la reforma electoral en el Estado de Coahuila, misma que fue resuelta el 5 de noviembre de $2007 .{ }^{29}$ En dicho medio de control constitucional, entre otros aspectos, se alegaba la inconstitucionalidad del artículo 15, fracción IX de la Ley de Instituciones Políticas y Procedimientos del Estado de Coahuila. ${ }^{30}$ Para efectos de resolver el mecanismo de protección constitucional de referencia, el Tribunal Pleno solicitó a la Sala Superior del Tribunal Electoral del Poder Judicial de la Federación su Opinión, en términos de lo dispuesto por el artículo 68, segundo párrafo de la Ley Reglamentaria de las Fracciones I y II del artículo 105 de la Constitución Política de los Estados Unidos Mexicanos. ${ }^{31}$

Cabe señalar que, en la opinión de mérito, la referida Sala precisó que la norma impugnada indebidamente restringía el derecho a ser votado al ser una norma no razonable ni proporcional. Además de que tampoco se justificaba dicha hipótesis como una causa de inelegibilidad debido a que estas están fundadas en cuestiones excepcionales.

Al respecto, el Alto Tribunal concluyó que la normativa tildada de inconstitucional por los promotores afectaba el derecho fundamental de ser votado, consagrado en el numeral 35, fracción II de la Carta Magna, en cuya hipótesis normativa se establece que el ciudadano puede ser votado para cualquier otro empleo o comisión, teniendo las calidades que establezca la ley, entendidas dichas calidades como el perfil de una persona, que vaya a ser nombrada en el empleo, cargo o comisión de que se trate, que puede ser: capacidad, aptitudes, preparación profesional, edad y demás circunstancias, que pongan en relieve el perfil idóneo para desempeñar con eficiencia y eficacia el empleo o comisión que se le asigne. ${ }^{32}$ Ello, toda vez que la norma impugnada restringía de manera irrazonable el derecho a ser votado, pues la pertenencia a un partido político distinto de aquel que lo postulara, no puede considerarse como una calidad necesaria para ejercer el cargo, máxime que la única restricción para el ejercicio de este derecho está condicionada a los aspectos intrínsecos del ciudadano y no así a los extrínsecos a este.

29 Suprema Corte de Justicia de la Nación, Acción de Inconstitucionalidad 158/2007 y sus acumuladas 159/2007, 160/2007, 161/2007 y 162/2007, 5 de noviembre de 2007, en www.dof.gob.mx/ nota_to_doc.php?codnota=5054505.

30 El artículo en comento establecía que es requisito para desempeñar un cargo de elección popular el no haber sido integrante, en los términos de los estatutos correspondientes, de un partido político distinto al que lo postula cuando menos dos años antes de la fecha de registro de candidatos de la elección de que se trate.

31 Congreso de la Unión, Ley Reglamentaria de las Fracciones I y II del artículo 105 de la Constitución Política de los Estados Unidos Mexicanos, en http://www.diputados.gob.mx/LeyesBiblio/ pdf/205_270115.pdf.

32 En dicha ejecutoria, la Suprema Corte señaló que el alcance que el constituyente atribuyó al concepto "calidades que establezca la ley", es el de considerarlas como circunstancia inherente a la persona misma que los ciudadanos pretendan ocupar un cargo de elección popular, con lo que evidentemente excluye otro tipo de atributos o circunstancias que no sean esenciales o intrínsecas al sujeto en cuestión. 
Además, el Tribunal Electoral del Poder Judicial de la Federación, la máxima autoridad jurisdiccional en materia electoral, conoció de tres asuntos en los que subyacen aspectos importantes relacionados con ciertos matices de transfuguismo. En los expedientes identificados con las claves ST-JRC-142/2015, STJRC-143/2015 y ST-JDC-492/2015, del índice de la Sala Regional Toluca del Tribunal Electoral del Poder Judicial de la Federación, ${ }^{33}$ la Sala de Mérito argumentó que, en virtud de la reforma constitucional en materia política-electoral del 2014, la prohibición de no postular candidatos de otro partido político fue elevada a rango constitucional, por lo que ya no se trataba de una cuestión de mera legalidad y sujeta al principio de definitividad ${ }^{34}$ de las etapas del proceso electoral, sino que se trataba de un verdadero principio constitucional en materia electoral que se encontraba implícito en los artículos 59, 115, fracción I, y 116, fracción III, de la Constitución General de la República y que la Sala Regional en comento denominó "principio constitucional de institucionalidad partidaria y política".

En esa linea argumentativa, la referida Sala Regional consideró que se encontraban en colisión dos principios constitucionales en materia electoral, por un lado, el principio de definitividad y, por el otro, el que denominó como principio constitucional de institucionalidad partidaria y política, por lo que estableció que se debía realizar un ejercicio de ponderación para conocer cuál de los dos citados principios debía prevalecer; de esta manera, la referida Sala estableció que el principio constitucional de institucionalidad partidaria y política era el que prevalecía.

Por lo anterior, la Sala Regional concluyó que no existía impedimento jurídico para que en la etapa de resultados y validez de la elección revisara la vulneración o no al principio de institucionalidad partidaria y politica.

33 Tribunal Electoral del Poder Judicial de la Federación, sentencia de los expedientes STJRC-142/2015. ST-JRC-143/2015 y ST-JDC-492/2015, 24 de agosto de 2015, en http://www. te.gob.mx/salasreg/ejecutoria/sentencias/toluca/ST-JRC-0142-2015.pdf

Para el proceso electoral local 2014-2015, en el Estado de Michoacán, específicamente en la elección del Ayuntamiento de Tarimbaro, Michoacán, los partidos políticos de la Revolución Democrática, del Trabajo y Encuentro Social decidieron competir en candidatura común encabezada por Baltazar Gaona Sánchez, por lo que presentaron ante el Instituto Electoral de Michoacán su solicitud, la cual fue aprobada en el acuerdo CG/134/2015. Es importante señalar que, previo a la designación de la candidatura común de los Partidos Políticos, señalados en supra líneas, el C. Baltazar Gaona Sánchez compitió en el proceso interno del Partido de la Revolución Democrática, del cual resultó el ganador.

Sin embargo, el proceso interno del Partido de la Revolución Democrática fue impugnado, y mediante sentencia recaída en el Juicio para la Protección de los Derechos Político-Electorales del Ciudadano ST-JDC-211/2015, se determinó que había un cambio en el ganador del citado proceso intrapartidario por lo que se le otorgaba el triunfo al C. Alfredo Jiménez Baltazar.

En ese orden de ideas, como consecuencia de la determinación señalada, se dejó sin efectos el acuerdo CG/134/2015 aprobado por el Consejo General del Instituto Electoral de Michoacán, únicamente por lo que hace a la aprobación de registro de la planilla de candidatos a presidente municipal, síndico y regidores postulada por el Partido de la Revolución Democrática para el Ayuntamiento de Tarimbaro, Michoacán.

Por lo anterior, los partidos del Trabajo y Encuentro Social decidieron mantener la candidatura común encabezada por el C. Baltazar Gaona Sánchez, y, por ende, dar por concluida la candidatura común que se había establecido con el Partido de la Revolución Democrática.

34 Entendido como aquel en el que las etapas del proceso electoral se van agotando una a una y, una vez agotadas, no se pueden retrotraer los efectos a las anteriores. 
Así las cosas, la Sala Regional Toluca al resolver el asunto de referencia, concluyó que se acreditaba la causal de nulidad de la elección por violación de principios constitucionales, específicamente por la violación del Partido del Trabajo y del Partido Encuentro Social del principio constitucional de institucionalidad partidaria y política, realizada con la postulación del candidato, lo anterior toda vez que dicho candidato pertenecía a una fuerza politica con la cual se había identificado desde el proceso de selección interna -Partido de la Revolución Democrática-, y posteriormente fue apoyado por otros dos institutos políticos nacionales diversos, lo que se traducía en un quebrantamiento de la equidad en la contienda electoral, $\mathrm{y}$, por ende, la referida instancia federal determinó declarar la invalidez de la elección de miembros del ayuntamiento del municipio de Tarímbaro, perteneciente al estado de Michoacán de Ocampo.

Ahora bien, dentro de la cadena impugnativa, la Sala Superior del referido órgano jurisdiccional federal resolvió los recursos de reconsideración SUP-REC-616/2015, SUP-REC-623/2015 y SUP-REC-624/2015 acumulados, ${ }^{35}$ determinando revocar la resolución emitida por la Sala Regional Toluca, toda vez que desde su perspectiva dicha Sala Regional, de manera errónea, amplió la prohibición establecida para la figura de la reelección para supuestos que no están previstos expresamente en la Constitución General de la República, por lo que violentó lo establecido en el artículo 1 constitucional, consistente en la obligación de interpretar las normas, buscando maximizar el ejercicio de los derechos fundamentales.

Adicionalmente, la referida Sala Superior estableció que al no estar acreditada la violación a lo dispuesto por las normas constitucionales señaladas, toda vez que no resultaban ser aplicables al asunto en comento, era evidente que no existió la infracción constitucional aducida por la Sala Regional, esto es, no existió violación al principio que dicha Sala denominó como principio constitucional de institucionalidad partidaria y politica.

Aunado a lo anterior, otro ejemplo paradigmático del tema en estudio es el relativo a los recursos de apelación identificados con las claves SUP-RAP-125/2015, SUPRAP-128/2015, SUP-RAP-129/2015, SUPRRV-9/2015 y SUP-RRV-10/2015, ${ }^{36}$ en

35 Tribunal Electoral del Poder Judicial de la Federación, sentencia de los expedientes SUPREC-616/2015, SUP-REC-623/2015 y SUP-REC-624/2015 Acumulados, 31 de agosto de 2015, en http://www.te.gob.mx/Informacion_juridiccional/sesion_publica/ejecutoria/sentencias/SUPREC-0616-2015.pdf.

La Sala Superior del Tribunal Electoral del Poder Judicial de la Federación analizó la sentencia emitida por la Sala Regional Toluca en el expediente ST-JRC-142/2015 y Acumulados, en la que se había decretado la nulidad de la elección del ayuntamiento de Tarímbaro, Michoacán, por la violación al principio constitucional de institucionalidad partidaria y política, toda vez que la planilla ganadora fue la registrada por los partidos políticos nacionales del Trabajo y Encuentro Social, los cuales, en candidatura común, registraron como su candidato al puesto de presidente municipal al C. Baltazar Gaona Sánchez, quien era militante y había participado en el proceso interno del Partido de la Revolución Democrática.

10036 TriBunal Electoral del Poder Judicial de la Federación, sentencia de los expedientes SUP29 de abril de 2015, http://www.te.gob.mx/Informacion_juridiccional/sesion_publica/ejecutoria/ sentencias/SUP-RAP-0125-2015.pdf. 
los cuales la Sala Superior del Tribunal Electoral del Poder Judicial de la Federación determinó que los agravios resultaban fundados en virtud de que se acreditó plenamente que el ciudadano Marcelo Luis Ebrard Casaubón participó en los procesos internos de selección de candidatos tanto del Partido de la Revolución Democrática como del Partido Movimiento Ciudadano, mediante la realización de actos apoyados en propuestas politicas diferentes y que son tendentes a colocarlo en un plano de ventaja sobre los demás aspirantes, vulnerando el artículo 227, apartado 5, de la Ley General de Instituciones y Procedimientos Electorales, así como el principio de equidad en la contienda electoral.

Asimismo, la Sala Superior estableció que el registro del ciudadano Marcelo Luis Ebrard Casaubón resultaba ilegal debido a que también vulneraba el artículo 238, apartado 3, de la Ley General de Instituciones y Procedimientos Electorales, en virtud de que el partido Movimiento Ciudadano había violentado su normatividad interna, toda vez que el ciudadano en referencia fue electo como candidato a diputado federal por dicho partido político nacional, sin que se hubiera inscrito como aspirante o precandidato interno o externo, violentando la convocatoria que para tales efectos habia emitido la propia entidad de interés público en comento. Finalmente, un ejemplo dado en fechas recientes, y que si bien no tiene relación, como en los casos abordados con antelación, con el tema del transfuguismo en la fase de candidatura, sí guarda relación directa con dicho fenómeno en la fase del desempeño del cargo. Esto es, a partir de los resultados electorales de la elección intermedia del año 2015, algunos senadores, pertenecientes a la LXIII Legislatura que inició su ejercicio constitucional en el año 2012 y que deberá concluir en el 2018, del Partido Político Nacional del Trabajo, en virtud de que el instituto político de referencia no había alcanzado el umbral del tres por cierto de la votación válida emitida para la conservación de su registro como partido político nacional ${ }^{37}$, vislumbraron la posibilidad de abandonar la bancada de dicho instituto político para conformar la del Partido Político Nacional Morena e incluso denominar a la existente PT-Morena. Sin embargo, dicha circunstancia no aconteció toda vez que, finalmente, el Instituto Nacional Electoral, después de varios precedentes

El 4 de abril de 2015, el Consejo General del Instituto Nacional Electoral emitió el acuerdo INE/ CG162/2015, mediante el cual aprobó el registro de Marcelo Luis Ebrard Casaubón como candidato a diputado federal, postulado por el partido político nacional Movimiento Ciudadano, mediante el principio de representación proporcional en la cuarta circunscripción plurinominal electoral. Por lo que los Partidos Políticos Nacionales Nueva Alianza, Verde Ecologista de México y Encuentro Social promovieron ante la Sala Superior del Tribunal Electoral del Poder Judicial de la Federación un recurso de apelación, en el que alegaban que dicho acuerdo del Consejo General violaba las prohibiciones contenidas en los artículos 227, apartado 5, y 238, apartado 3, ambos de la Ley General de Instituciones y Procedimientos Electorales, relativas a que los ciudadanos participen de manera simultánea en dos procesos de selección interna de dos partidos políticos, y que los partidos políticos respeten sus normas internas al solicitar el registro de sus candidatos. Véase Instituto Nacional Electoral, Acuerdo INE/CG/162/2015, 4 de abril de 2015, en http://portalanterior.ine.mx/archivos3/portal/historico/recursos/IFE-v2/DS/DS-CG/DS-SesionesCG/CG-acuerdos/2015/04_Abril/CGesp201504-04/CG_esp_201504-4_ap_1.pdf

37 El cuarto párrafo de la fracción I del párrafo segundo del artículo 41 de la Constitución Política de los Estados Unidos Mexicanos establece que el partido político nacional que no obtenga, al menos, el tres por ciento del total de la votación válida emitida en cualquiera de las elecciones que se celebren para la renovación del Poder Ejecutivo o de las Cámaras del Congreso de la Unión, le será cancelado el registro. 
judiciales resueltos por la Sala Superior, determinó que el Partido del Trabajo acreditó haber obtenido un porcentaje de votación válida emitida superior al tres por cierto, por lo que conservaba su registro como Partido Político Nacional. ${ }^{38}$

\section{CONCLUSIONES}

El fenómeno del transfuguismo, con independencia de que se aborde en el sistema presidencial o el parlamentario, no solo representa una afrenta a la representación política, sino que se convierte en un problema de indole constitucional para el Estado, ante la tentación del legislador de regularlo, quizá impulsado por la hegemonía que aún ejercen los partidos políticos, para su acotación en lo referente a la migración parlamentaria e incluso en la fase de la candidatura, como ya aconteció en el caso mexicano, en el ámbito legislativo, con la reforma a la legislación electoral local del Estado de Coahuila, o la diversa Constitución federal en materia política-electoral, publicada en el Diario Oficial de la Federación el 10 de febrero de 2014.

Efectivamente, la reforma federal de referencia nació de la necesidad de transitar de una democracia electoral a una democracia de resultados. Ello dado que, según se adujo en las amplias explicaciones dadas con motivo de la reforma en cita, en el sistema político no se propiciaban los acuerdos ni la corresponsabilidad entre poderes, y esto no permitía gobernar con eficacia. Por lo que, para poder tener una democracia de resultados, era necesario que los representantes de los ciudadanos en los cargos públicos tuvieran un mayor acercamiento a estos, y que pudiera existir un mecanismo diferente de rendición de cuentas.

En ese sentido, se generó con ciertos matices la figura de la reelección de las autoridades - denominada elección consecutiva- como un instrumento del ciudadano para evaluar el desempeño del gobernante. No obstante, también buscó que

38 Notimex, "En el Senado existe bancada del PT-Morena, dice Bartlett”, Excélsior, 2 de septiembre de 2015, en http://www.excelsior.com.mx/nacional/2015/09/02/1043623

El 23 de octubre de 2015, la Sala Superior del Tribunal Electoral del Poder Judicial de la Federación resolvió el expediente relativo al Recurso de Apelación SUP-RAP-654/2015, en el que dejó sin efectos jurídicos la declaratoria de pérdida de registro del Partido del Trabajo como partido político nacional. Véase Tribunal Electoral del Poder Judicial de la Federación, sentencia del expediente SUP-RAP-654/2015 y acumulados, 23 de octubre de 2015, en http://portal.te.gob.mx/colecciones/sentencias/html/SUP/2015/RAP/SUP-RAP-00654-2015.htm

En la sentencia correspondiente al expediente SUP-RAP- 756/2015, la Sala Superior ya citada determinó la inaplicación de diversas disposiciones normativas de la Ley General de Partidos Políticos y de la General de Instituciones y Procedimientos Electorales. Véase Tribunal Electoral del Poder Judicial de la Federación, sentencia del expediente SUP-RAP-756/2015, 2 de diciembre de 2015, http://www.te.gob.mx/Informacion_juridiccional/sesion_publica/ejecutoria/sentencias/ SUP-RAP-0756-2015.pdf.

Se recomieda la lectura del acuerdo INE/CG/1049/2015 del 16 de diciembre de 2015, en el que se determina que el Partido del Trabajo conserva su registro como partido político nacional. Véase Instituto Nacional Electoral, acuerdo INE/CG/1049/2015, http://dof.gob.mx/nota_detalle.php?c odigo $=5452183 \&$ fecha $=09 / 09 / 2016$

Cfr. artículo 41, fracción I, párrafo 4 de la Constitución Política de los Estados Unidos Mexicanos en relación con el diverso 94, párrafo 1, inciso b) de la Ley General de Instituciones y Procedimientos Electorales. 
este se convirtiera en un instrumento de los partidos politicos para mantener la lealtad partidaria y acotar la libertad de participación politica, bajo las especificaciones que precisa la propia Constitución Mexicana, y que fueron retomadas en la legislación secundaria, como es el caso de quien busque reelegirse sea, en esencia, postulado nuevamente por el partido político que inicialmente lo postuló para el cargo que en ese momento desempeña, buscando con ello que, al menos en el caso de los legisladores, estos se mantengan integrados en la fracción parlamentaria del partido que los postuló, puesto que, en caso de convertirse en tránsfugas, limitaría su posibilidad de competir, bajo la regla de referencia, por lograr la elección consecutiva.

Adicionalmente, a nivel jurisdiccional se han emitido precedentes tendentes a privilegiar la lealtad con el partido político y restringir el derecho fundamental del ciudadano de votar y ser votado, estableciendo mayores restricciones a las que constitucionalmente son permitidas, aunque estos, en la última instancia revisora, no han pasado el tamiz de constitucionalidad. Sin embargo, ello deja más dudas que certezas puesto que aún sigue latente la posibilidad de que, en el futuro inmediato o mediato, se privilegie la lealtad partidaria sobre la libertad de participación política.

De lo antes señalado se colige que el actual andamiaje constitucional del Estado mexicano, si bien está diseñado para el fortalecimiento de las instituciones, entre las que se encuentran los partidos politicos, presenta atisbos de interés por fortalecer la participación electoral del gobernado, pero ello no resulta suficiente puesto que debe buscar un mejor equilibrio en aras de permitir una mayor participación al ciudadano en la vida pública del país.

Finalmente, a partir de los precedentes judiciales en México que han sido expuestos en el presente trabajo, no resulta dable la restricción de los derechos políticos del ciudadano mediante la regulación del transfuguismo, aun cuando el objetivo de esta sea la permisión de que los institutos políticos continúen manteniendo el monopolio en el dictado de las reglas que regulan el juego democrático y, en caso de que ello aconteciere, el papel del juez constitucional adquiere relevancia para maximizar la tutela judicial de los derechos fundamentales en materia política, ello a partir de analizar, bajo criterios de razonabilidad y proporcionalidad, las restricciones legislativas en materia de transfuguismo.

\section{BIBLIOGRAFÍA}

Bovero, Michelangelo, "La protección supranacional de los Derechos Fundamentales y la Ciudadanía”, en Cuadernos de divulgación de la justicia electoral 19, México, Tribunal Electoral del Poder Judicial de la Federación, 2013.

BRunet, Pierre, "Acerca del concepto de representación política”, en Revista internacional de pensamiento politico 7 (2012), en http://pensamientopolitico.org/ Descargas/RIPP07245261.pdf Fecha de consulta: 14 de agosto de 2015. 
CARPIzo, Jorge, "Características esenciales del sistema presidencial e infuencias para su instauración en América Latina”, en Cuestiones Constitucionales 115, en http://historico.juridicas.unam.mx/publica/rev/boletin/cont/115/art/ art2.htm Fecha de consulta: 14 de agosto de 2015.

Congreso de la República de Colombia, Glosario, en http://www.senado.gov.co/ glosario/Glosario-1/I/ Fecha de consulta: 19 de septiembre de 2015.

Congreso de la Unión, Constitución Política de los Estados Unidos Mexicanos, en http://www.diputados.gob.mx/LeyesBiblio/index.htm Fecha de consulta: 19 de septiembre de 2015.

Congreso de la Unión, Ley General de Instituciones y Procedimientos Electorales, en http://www.diputados.gob.mx/LeyesBiblio/index.htm Fecha de consulta: 19 de septiembre de 2015.

Congreso de la Unión, Ley General de Partidos Políticos, en http://www.diputados.gob.mx/LeyesBiblio/index.htm

Congreso de la Unión, Ley Reglamentaria de las Fracciones I y II del artículo 105 de la Constitución Política de los Estados Unidos Mexicanos, en http://www. diputados.gob.mx/LeyesBiblio/pdf/205_270115.pdf Fecha de consulta: 13 de julio de 2015 .

Convención Americana sobre Derechos Humanos, en http://www.bjdh.org.mx/interamericano/busqueda?q=restricci\%F3n\%20de\%20derechos\&or=true\#mapa_listado Fecha de consulta: 13 de julio de 2015.

Corte Constitucional de la República de Colombia, sentencia C-334, de 4 de junio de 2014, en http://www.corteconstitucional.gov.co/RELATORIA/2014/C-334-14.htm Fecha de consulta: 13 de julio de 2015.

CORTE Interamericana de Derechos Humanos, Caso Argüelles y otros vs. Argentina. Excepciones Preliminares, Fondo, Reparaciones y Costas. Sentencia de 20 de noviembre de 2014. Serie C No. 288, párr. 221.

CoRTe Interamericana de Derechos Humanos, Caso Castañeda Gutman vs. Estados Unidos Mexicanos. Excepciones Preliminares, Fondo, Reparaciones y Costas. Sentencia de 6 de agosto de 2008. Serie C No. 184, párr. 140.

CoRTe Interamericana de Derechos Humanos. Caso Yatama vs. Nicaragua. Excepciones Preliminares, Fondo, Reparaciones y Costas. Sentencia de 23 de junio de 2005, en http://www.corteidh.or.cr/docs/casos/articulos/seriec_127_esp.pdf Fecha de consulta: 4 de agosto de 2015.

CRIADO de Diego, Marcos, "Sobre el concepto de representación política: lineamientos para un estudio de las transformaciones de la democracia representativa", en Revista Derecho del Estado 28 (2012), en http://revistas.uexternado.edu.co/ index.php/derest/article/view/3180 Fecha de consulta: 4 de agosto de 2015.

104 De Esteban, Jorge, "El fenómeno español del transfuguismo político y la jurisprudencia constitucional”, en Revista de estudios politicos 70 (1990), en http:// 
webcache.googleusercontent.com/search?q=cache:9mcugzpzg14J:dialnet.unirioja.es/descarga/articulo/27081.pdf $+\& c d=1 \&$ hl=es\&ct=clnk\&gl=mx Fecha de consulta: 4 de agosto de 2015.

DeNIS, P. y Jean-Paul VARGAS, cultura parlamentaria y disciplina partidaria: la institucionalidad informal del transfuguismo en Centroamérica, en www.ort.edu. uy/facs/.../95/culturaparlamentariaydisciplinapartidaria.doc Fecha de consulta: 4 de agosto de 2015.

Espinoza Toledo, Ricardo, "Sistemas parlamentario, presidencial y semipresidencial", en Cuadernos de divulgación de la cultura democrática 20 (2012).

InstituTo de Investigaciones Legislativas del Senado de la República, Parlamentarismo y presidencialismo. Estudio comparado, en http://www.senado.gob. $\mathrm{mx} / \mathrm{ibd} /$ content/lineas/docs/varios/Parlamentarismo_Presidencialismo.pdf Fecha de consulta: 25 de julio de 2015

InstrtuTo Nacional Electoral, Acuerdo INE/CG/162/2015, 4 de abril de 2015, en http://portalanterior.ine.mx/archivos3/portal/historico/recursos/IFE-v2/ DS/DS-CG/DS-SesionesCG/CG-acuerdos/2015/04_Abril/CGesp201504-04/ CG_esp_201504-4_ap_1.pdf

InSTITUTo Nacional Electoral, Acuerdo INE/CG/1049/2015, 16 de diciembre de 2015, en http://dof.gob.mx/nota_detalle.php?codigo=5452183\&fecha=09/09/2016

JimÉnEz BADILLo, Margarita, Transfuguismo legislativo en Centroamérica, en http:// www.somee.org. $\mathrm{mx} /$ download.php?t=2\&c=3\&h=1066d7ae92e1d5621c6f1cb2 le976306acdc37fe

Nohlen, Dieter, "El presidencialismo comparado", en Revista Instituto de Altos Estudios Europeos 1, en http://www.iaee.eu/riaee/num1/riaeelart1.pdf

Notimex, "En el Senado existe bancada del PT-Morena, dice Bartlett", Excélsior, 2 de septiembre de 2015, en http://www.excelsior.com.mx/nacional/2015/09/02/1043623

Perícola, María Alejandra y Gonzalo Joaquín Linares, "El transfuguismo político como elemento distorsionador de la representación política", en Revista pensar en Derecho, en http://www.derecho.uba.ar/publicaciones/pensar-en-derecho/ revistas/3/el-transfuguismo-politico-como-elemento-distorsionador-de-larepresentacion-politica.pdf

Roca TRias, Encarnación y M $\mathrm{M}^{\text {a }}$ Angeles AHumada Ruz, Los principios de razonabilidad y proporcionalidad en la jurisprudencia constitucional española, en http:// www.tribunalconstitucional.es/es/actividades/Documents/XV\%20Trilateral/ PONENCIA.pdf Fecha de consulta: 9 de septiembre de 2015.

Secretaría de Gobernación, Diario Oficial de la Federación. Decreto por el que se derogan, reforman y adicionan diversas disposiciones de la Constitución Política de los Estados Unidos Mexicanos, en materia politica-electoral, 10 de febrero de 2014, en http://www.dof.gob.mx/nota_detalle.php?codigo=5332025\&fec ha=10/02/2014 Fecha de consulta: 9 de septiembre de 2015. 
Suprema Corte de Justicia de la Nación, Acción de Inconstitucionalidad 158/2007 y sus acumuladas 159/2007, 160/2007, 161/2007 y 162/2007, 5 de noviembre de 2007, en www.dof.gob.mx/nota_to_doc.php?codnota=5054505 Fecha de consulta: 9 de septiembre de 2015.

Tribunal Electoral del Poder Judicial de la Federación, sentencia del expediente SUP-JDC-695/2015, 6 de julio de 2007, en http://www.te.gob.mx/documentacion/publicaciones/Serie_comentarios/09_SUP-JDC-0695-2007.pdf Fecha de consulta: 9 de septiembre de 2015.

Tribunal Electoral del Poder Judicial de la Federación, sentencia de los expedientes SUP-RAP-125/2015, SUP-RAP-128/2015, SUP-RAP-129/2015, SUPRRV-9/2015 Y SUP-RRV-10/2015, 29 de abril de 2015, en http://www.te.gob. $\mathrm{mx} /$ Informacion_juridiccional/sesion_publica/ejecutoria/sentencias/SUPRAP-0125-2015.pdf Fecha de consulta: 9 de septiembre de 2015.

Tribunal Electoral del Poder Judicial de la Federación, sentencia de los expedientes ST-JRC-142/2015. ST-JRC-143/2015 y ST-JDC-492/2015, 24 de agosto de 2015, en http://www.te.gob.mx/salasreg/ejecutoria/sentencias/toluca/STJRC-0142-2015.pdf Fecha de consulta: 13 de julio de 2015.

Tribunal Electoral del Poder Judicial de la Federación, sentencia de los expedientes SUP-REC-616/2015, SUP-REC-623/2015 y SUP-REC-624/2015 Acumulados, 31 de agosto de 2015, en http://www.te.gob.mx/Informacion_juridiccional/ sesion_publica/ejecutoria/sentencias/SUP-REC-0616-2015.pdf

Tribunal Electoral del Poder Judicial de la Federación, sentencia del expediente SUPRAP-654/2015 y acumulados, 23 de octubre de 2015, en http://portal.te.gob. $\mathrm{mx} /$ colecciones/sentencias/html/SUP/2015/RAP/SUP-RAP-00654-2015.htm

Tribunal Electoral del Poder Judicial de la Federación, sentencia del expediente SUP-RAP-756/2015, 2 de diciembre de 2015, en http://www.te.gob. $\mathrm{mx} /$ Informacion_juridiccional/sesion_publica/ejecutoria/sentencias/SUPRAP-0756-2015.pdf

Weidenslaufer, Christine, Transfugismo politico. Derecho comparado. Biblioteca del Congreso Nacional de Chile, en https://www.bcn.cl/asesoriasparlamentarias/ buscar?texto=Transfugismo+pol\%C3\%ADtico.+Derecho+Comparado Fecha de consulta: 13 de julio de 2015.

WoldenBerg, José y Ricardo BecerRA, "Representación politica", en Diccionario Electoral, Centro de Asesoría y Promoción Electoral del Instituto Interamericano de Derechos Humanos, en http://www.iidh.ed.cr/comunidades/redelectoral/docs/ red_diccionario/representacion\%20politica.htm Fecha de consulta: 13 de julio de 2015.

ZovatTo, Daniel, Reforma politico-electoral e innovación institucional en América Latina durante la tercera ola democrática (1978-2009), en http://eprints.ucm. es/17751/1/T34113.pdf Fecha de consulta: 13 de julio de 2015. 